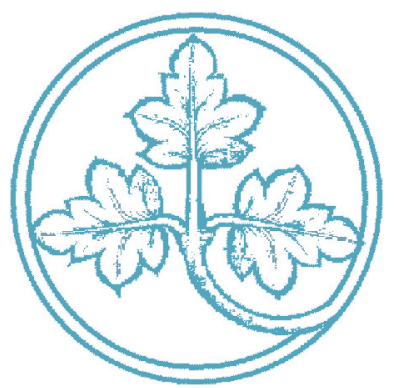

Institutional communication revisited: Preferences, opportunity structures and scientific expertise in policy networks

Philip Leifeld

Volker Schneider

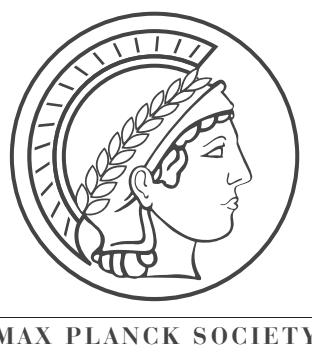




\section{Institutional communication revisited: Preferences, opportunity structures and scientific expertise in policy networks}

Philip Leifeld / Volker Schneider

April 2010 


\title{
Institutional communication revisited: Preferences, opportunity structures and scientific expertise in policy networks*
}

\author{
Philip Leifeld ${ }^{\dagger} \quad$ Volker Schneider ${ }^{\ddagger}$
}

April 26, 2010

\begin{abstract}
Information exchange in policy networks is usually attributed to preference similarity, influence reputation, social trust and institutional actor roles. We suggest that political opportunity structures and transaction costs play another crucial role and estimate a rich statistical network model on tie formation in the German toxic chemicals policy domain. The results indicate that the effect of preference similarity is absorbed by other determinants while opportunity structures indeed have to be taken into account. We also find that different types of information exchange operate in complementary, but not necessarily congruent, ways.
\end{abstract}

\section{Motivation}

The question how policy networks operate has provoked a substantial number of policy network studies over the course of the last 30 years (Leifeld, 2007). Some of the more recent analyses have tried to assess the reasons why political actors establish contacts to some actors but not to others. Particularly ideology (Henry et al., 2010; Laumann et al., 1992), preference similarity on political issues (Weible and Sabatier, 2005; Zafonte and Sabatier, 1998; König

*The authors wish to thank Martin F. Hellwig, Christoph Engel, Andreas Glöckner, Ben Domingue and Beaugitte Laurent for helpful comments.

${ }^{\dagger}$ Max Planck Institute for Research on Collective Goods, Kurt-Schumacher-Str. 10, 53113 Bonn, Germany. E-mail: Leifeld@coll.mpg.de.

$\ddagger$ Department of Politics and Management, Box D 81, University of Konstanz, 78457 Konstanz, Germany. E-mail: Volker.Schneider@uni-konstanz.de. 
and Bräuninger, 1998; Carpenter et al., 2004), preference dissimilarity (Stokman and Zeggelink, 1996; Stokman and Berveling, 1998), functional or institutional interdependence (Zafonte and Sabatier, 1998; König and Bräuninger, 1998), social trust (Carpenter et al., 2004; Henry et al., 2010) and perceived influence (Weible and Sabatier, 2005; Stokman and Zeggelink, 1996; Stokman and Berveling, 1998) have been found to be drivers of tie formation in policy networks. These findings have been obtained by conducting quantitative case studies of several policy domains or subsystems like San Francisco Bay-Delta water policy (Zafonte and Sabatier, 1998), California marine protected area policy (Weible and Sabatier, 2005), the U.S. health policy and energy policy sectors (Carpenter et al., 2004; Laumann et al., 1992), U.S. agricultural policy and labor policy (Laumann et al., 1992), and the German labor policy domain (König and Bräuninger, 1998).

In contrast to some of these studies, we argue that preference similarity does not predict tie formation sufficiently well. Instead, we posit that opportunity structures as proposed by Huckfeldt and Sprague (1987) in the context of individual (non-elite) discussion networks exert a strong influence on the communication between actors. We derive this hypothesis from resource dependence theory, mobilization theory of social movements, and the transaction cost approach. Establishing contacts is apparently not trivial, so actors have to rely on institutionalized venues like policy-related committees, and make use of already existing channels of communication.

Moreover, tie formation is qualified by the type of information exchange under scrutiny. This point has been neglected by other studies conducted so far. Scientific or technical information exchange, on the one hand, and political or strategic information exchange, on the other hand, may serve quite different purposes. Exchange on technical matters is important since many policy problems are growing increasingly complex and technical. As Heclo $(1978,103)$ observed back in 1978, "knowing what is right becomes crucial, and since no one knows that for sure, going through the process of dealing with those who are judged knowledgeable [...] becomes even more crucial." We would thus expect scientific actors to be much more attractive contacts for organizations in the technical information exchange network.

We examine these points by analyzing political and technical information exchange in the policy domain of toxic chemicals regulation in Germany in the 1980s. Previous work on this policy network by the authors (Schneider, 1988; Schneider and Leifeld, 2009) has revealed that actors who occupy central positions in the information exchange network also maintain policy positions closer to the final policy outcome. This correlation suggests that embeddedness in the information exchange network may be advantageous for organized interests. In the light of this policy-relevant finding, it is interest- 
ing to know what drives centrality in the communication network, or more broadly, what determines whether two organizations actually exchange information or not. In doing so, we combine several hypotheses from relevant literature (see above) and add our own hypotheses regarding opportunity structures and the role of scientific expertise on top of that. The primary goal is to find a model that explains network formation sufficiently well. To the best of our knowledge, this is the first time that all of the presumably relevant hypotheses are included in a single model and that dyadic dependence is explicitly taken into account. Our secondary goal is to estimate the relative contribution of each of the hypothesized factors.

Our paper is structured as follows: in section 2, we review the literature on tie formation in policy networks and derive testable hypotheses and control variables. Section 3 introduces the policy domain under scrutiny, the data collection process, our variables, and the methodology of exponential random graph models that we employ. In section 4, we will present the results of our analysis and discuss the model fit. The final section 5 puts the results into perspective and suggests further theoretical and empirical pathways.

\section{Explaining information exchange}

State-centric approaches to policy-making assume that public policies are designed and implemented by governmental actors like the parliament and administrative agencies. The policy network approach, in contrast, assumes that public policy-making and implementation are also affected by a variety of societal or political actors like interest groups, scientific organizations, political parties, or international organizations (Adam and Kriesi, 2007). Public and private actors can maintain various empirically measurable relations like information or resource exchange, influence attribution, or common group membership. These structures are usually stable for several years; the analysis focuses on fairly persistent governance arrangements in a certain policy sector, or " $2^{\text {nd }}$ order economizing" in the words of Williamson (2000, 597). The relation of most interest in the literature on policy networks has been information exchange, which has sometimes been called "contactmaking" (Carpenter et al., 2004) or "policy network formation" (König and Bräuninger, 1998).

\subsection{Preference similarity}

There are two competing views on whether preference similarity between political elite organizations has a positive or a negative effect on the proba- 
bility of communication between them. In one of these perspectives, political actors seek alliances with like-minded actors.

The Advocacy Coalition Framework (Sabatier and Weible, 2007) provides an example. Roughly speaking, it posits that there are two or more coalitions in any policy subsystem which continuously try to convince each other of the optimal design of a policy. Policy core preferences are the "glue that binds coalitions together", i. e., policy-related beliefs are more similar within coalitions than they are across coalitions (Sabatier and Weible, 2007, 195). Accordingly, coordinated behavior is hypothesized to be much more prevalent within coalitions than between actors of different coalitions in the Advocacy Coalition Framework. Along these lines, empirical research has shown that "both belief congruence and functional interdependence are important for understanding coordination" (Zafonte and Sabatier, 1998, 473) and that "shared beliefs are the best predictor for policy network relationships" (Weible and Sabatier, 2005, 461).

The finding is corroborated by Carpenter et al. (2004), who examine the role of directed triads as well as preference similarity in contact-making networks between Washington lobbyists in the health sector and the energy sector. They conclude that "whether in health politics or energy politics, and whether the sample includes all organizations in a policy arena or just private organizations, preference similarity is an important determinant of information transmission in national politics" (Carpenter et al., 2004, 243). This result is interpreted in the light of signaling models between lobbyists and legislators, which predict "that information is transmitted credibly to the extent that the sender and receiver share policy preferences", and in the light of the mobilization of bias theory. According to the latter, "providing information subsidizes the receiver's activities, enabling her to become active in an issue at lower cost; groups strategically provide information to those with similar interests" (Carpenter et al., 2004, 226).

König and Bräuninger (1998) develop an explanatory model of information exchange between organized corporate actors in the German labor policy domain. Their results confirm the impact of the "distance between actors' preferences" on the "likelihood of network choice" (König and Bräuninger, 1998, 464). Two theoretical reasons are cited: first, since information is an "important power resource", actors are more inclined to inform their allies than their opponents. This is perfectly in line with the prediction of the Advocacy Coalition Framework that coordination takes place inside coalitions, but not between them. Second, König and Bräuninger $(1998,448)$ propose that preference similarity actually works via an intermediary variable, namely opportunity structures: like-minded actors meet each other frequently, and this promotes communication between them. In this article, we can test 
this claim more rigorously because we have recorded information about the preferences of actors and their membership in policy committees separately.

At the level of individual voters, analogous results have been obtained. Huckfeldt and Sprague $(1987,1213)$ conclude that "individuals do purposefully attempt to construct informational networks corresponding to their own political preferences." Unlike at the organizational level, the finding is explained by dissonance theory rather than power resources and coalitionbuilding. Psychological factors are presumably more important at the individual level if compared with organizations.

So far, both theoretical as well as empirical work has emphasized that shared preferences lead to information exchange because coordination on policy-related matters usually takes place between political allies. However, there is also a contrary view on preferences: in their policy maximization model, Stokman and Zeggelink (1996) and Stokman and Berveling (1998) simulate policy networks under the assumption that actors initiate contacts with other actors if they have opposite preferences. In their view, "actors can influence each other's policy positions (preferences) only through access relations. Access relations are therefore instrumental to obtain policy outcomes as close as possible to the own preferences" (Stokman and Zeggelink, 1996, 80). Consequently, if described as a spatial game, establishing contacts with similar actors in terms of preferences has no effect, and contact-making with actors who have more extreme positions in the same direction from the status quo is even counter-productive. Only access to other actors who have preferences beyond the status quo or between their ideal position and the status quo are efficient (Stokman and Zeggelink, 1996, 93).

For the same reasons, Austen-Smith and Wright (1992) assume in their competitive lobbying model that a lobbyist tends to inform a legislator of the appropriate policy design if the legislator has dissimilar preferences (c.f. Carpenter et al., 2004, 226, footnote 3).

The latter two models stress that actors have an incentive to convince their opponents by sending policy-related information to them. In this case, preference similarity should have a negative effect on network tie probability between actors. This runs counter to the empirical findings of the policy network literature presented before. ${ }^{1}$ How can these seemingly contrary hypotheses be reconciled?

\footnotetext{
${ }^{1}$ There is a third theoretical possibility: actors may initially have no opinion and may be convinced by other actors. Having no opinion, however, requires that an actor's interests are not at stake. In our conceptualization, how much an actor's interests are at stake is rather a separate dimension of policy-making. Hence we reserve this question for future research.
} 
We posit that the two views prevalent in the literature rest on two entirely different types of communication between political actors. In the first case, the contents of institutional communication is political or strategic information which is used by actors to coordinate their activities. Shared strategies can be conceived of as a power resource. The second type of communication is rather technical or scientific information about how the policy at issue could be designed. This type of information is more neutral and contains knowledge about the causes and consequences of a complex problem, policy goal priorities, and technical policy advice, often generated by scientific organizations in the first place and sent to interest groups or governmental actors. These ideal types correspond to the different types of policy advice described by Pielke (2007, 14), who distinguishes between the actor roles of an "issue advocate", who pursues policy goals, and an "honest broker", who is committed to objective truth. Both types of information are on a continuum, but we assume that it is possible to distinguish between them by employing standardized questions, albeit with some "noise".

The distinction between the two types of information makes the policy maximization hypothesis compatible with the Advocacy Coalition Framework, where technical policy analyses are used to justify one's own policy beliefs and to convince adversarial coalitions of the optimal policy choice (Sabatier, 1987). We can thus formulate two distinct hypotheses:

\section{Hypothesis 1 a: The power resource model}

The more similar the preferences of two actors, the more likely they are to exchange political/strategic information.

\section{Hypothesis $1 \mathrm{~b}$ : The policy maximization model}

The more similar the preferences of two actors, the less likely they are to exchange scientific/technical information.

\subsection{Technical and scientific expertise}

This leads to the question of government access. Conventional lobbying models assume that lobbying is asymmetric, meaning that interest groups exert an influence on decision-makers. In the model of Austen-Smith and Wright (1992), interest groups send information to governmental actors. In other theories of interest intermediation, organized interests try to exert pressure on the government (for an overview, see van Waarden, 1992). König and Bräuninger (1998) show empirically that disproportionally many information channels exist to public decision-makers. They explain their finding by citing neo-institutionalist arguments: "Public decision-makers take the final 
vote on public policies which are of interest to other actors with no formal voting power, and, thus, the latter will most likely try to get access to these public decision-makers" (König and Bräuninger, 1998, 449). Similarly, Carpenter et al. (2004, 232) "control for whether the [...] receiver [...] is a Governmental actor, since influential political actors are more likely to be contacted." However, they can confirm their hypothesis only in the energy sector, but not in health politics.

Considering the different types of information, we posit that technical information is frequently sent to governmental actors - in the narrow sense, e. g., federal ministries and administrative agencies - because this is consistent with the neo-institutionalist policy maximization model set out above. Interest groups are thereby likely to submit scientific information to the government in order to increase the chance that their views and opinions are codified into law. At the same time, decision-makers actively acquire technical knowledge from scientific actors and think tanks in order to increase the quality of their decisions or simply to obtain justification of their decisions (Sabatier, 1987, 650). On the other hand, the same transmission channel is used for the exchange of political and strategic information. Interest groups exchange such information with their allies and with those whom they seek to align with, all else being equal.

\section{Hypothesis 2 a: Governmental access}

Governmental actors have disproportionately many incoming information ties both in the scientific/technical and in the political/strategic information exchange network.

As mentioned in the previous paragraph, scientific actors generate knowledge and distribute it to other actors. Governmental actors are particularly inclined to receive specialized knowledge because they seek to make justified decisions. But scientific organizations are not constrained to submit their results to decision-makers. They rather have an interest in distributing their "product" to anyone who is interested, including international organizations, parties and interest groups. We therefore hypothesize that scientific actors maintain many outgoing information ties in the scientific information exchange network. This should not be the case when it comes to political and strategic information.

\section{Hypothesis 2 b: The role of scientific actors}

Scientific actors are particularly likely to send scientific/technical information to other actors, but they are not particularly likely to send political/strategic information. 


\subsection{Opportunity structures}

Besides collecting hypotheses from other empirical studies and putting them in a theoretical context, we also seek to make a genuinely new contribution to the theory of political communication among policy elites, which has not been tested before in an empirical analysis. The argument we would like to put forth is concerned with political opportunity structures.

As noted earlier on, in their interpretation of preference similarity, König and Bräuninger (1998) argue that common preferences are actually channeled via opportunity structures. If two actors have similar prefererences, they are more likely to meet each other frequently. And if they have the chance to exchange information at regular meetings, they will take this opportunity to team up with potential allies.

We argue that preference similarity and opportunity structures are two separable mechanisms, which contribute independently to network formation. Both variables may covary to a certain degree, but regular participation in meetings is rather an expression of an actor's interest in influencing policymaking, on the one hand, and its ability to participate in institutionalized policy committees, on the other. The idea is inspired by social movement research and mobilization theory, which alleges that political opportunity structures facilitate the ability of social movements to mobilize collectively (Kitschelt, 1986; Kriesi, 1995). Political opportunity structures "are comprised of specific configurations of resources, institutional arrangements and historical precedents for social mobilization, which facilitate the development of protest movements in some instances and constrain them in others" (Kitschelt, 1986, 58).

We define opportunity structures more narrowly as the ability of actors to communicate with each other without incurring transaction costs. If this is the case, actors should be more likely to exchange information than if information exchange is costly in terms of time, money or other resources. The argument is obviously borrowed from new institutional economics or more specifically from transaction cost theory, and particularly from the observation that institutionalized forms of exchange can be more efficient due to lower transaction costs in the long run (Williamson, 1991). This view is reflected by associational theories of interest intermediation like neocorporatism. Policy-making in institutionalized committees is regarded as a distinct form of governance beside communities, hierarchies and markets (Streeck and Schmitter, 1985).

Moreover, these hypotheses are compatible with resource dependence theory, which states that organizations have to establish contacts to other actors to maintain their survival in a world of scarce resources (Pfeffer and Salan- 
cik, 1978). The fewer resources they need to sacrifice in order to establish such a dependence relationship, the higher is the overall payoff of the actor to establish the link. Along the lines of mobilization theory, transaction cost theory, interest intermediation theories and resource dependence theory, we propose our next hypothesis:

\section{Hypothesis 3 a: Policy committees}

The more common policy committees two actors take part in, the more likely they are to exchange (both political/strategic and technical/scientific) information.

The reduction of transaction costs by using political opportunity structures can, however, occur via multiple channels. Opportunity structures are not necessarily institutionalized. A second test of the opportunity structure hypothesis can be easily achieved when taking into account that two different types of information exist and can be exchanged by actors. If actor A sends scientific information to actor B anyhow, there are virtually no costs associated with sending further information, such as strategic advice, and vice-versa.

\section{Hypothesis 3 b: Other communication channels}

If an actor sends political/strategic information to another actor, it is more likely also to send technical/scientific information to the other actor, and vice versa.

\subsection{Control variables}

There are several secondary hypotheses, most of which have been tested empirically before. We will include them as control variables in order to estimate a model of information exchange that is as complete as possible and that does not suffer from omitted variable bias.

\section{Interest group homophily}

The power resources model implies that interest groups are especially likely to share political or strategic information with other interest groups. We can expect this pattern because information exchange serves to coordinate activities in the pursuit of a common goal. Such a goal is nowhere else as pronounced as in lobbying groups because their very motivation is to change (or retain) the status quo. In other words, interest groups are more likely than other actors to seek alliances, both as a sender and receiver of strategic information, because their payoff from cooperating with others is 
higher. At the same time, interest groups are particularly attractive allies because their intrinsic motivation to attain policy goals is higher than the intrinsic motivation of other actors like, for example, scientific organizations. This results in mutual attachment between interest groups (in network terms "homophily", c.f. McPherson et al., 2001).

The policy maximization model makes the same prediction, but it results from a completely different mechanism: interest groups seek to convince their enemies, so they send them technical information about the appropriate policy design. Quite obviously, other interest groups are - if decision-makers are controlled for - the primary target of technical information because they are at the core of the adversarial coalition (Sabatier and Weible, 2007).

More generally speaking, in both models, interest groups have incentives to exchange information with each other because this is their institutional role. We therefore include a control variable for the homophily of interest groups, stating that interest groups are particularly likely to send (both scientific/technical and political/strategic) information to other interest groups.

\section{Perceived influence}

Besides the policy maximization model cited above, Stokman and Zeggelink (1996) also developed a competing model called the control maximization model. It is based on the assumption that actors seek access relations to other actors whom they perceive as powerful. They "estimate their likelihood of success by comparing their own resources with those of the target actors" (Stokman and Berveling, 1998, 582). When confronting this model with empirical data, however, Stokman and Berveling (1998, 595) find limited evidence: "The CM model clearly performs worse [than the policy maximization model]. This was found in other studies as well."

Quite to the opposite, Weible and Sabatier (2005) find a moderate effect of influence attribution on policy coordination and advice-seeking even when holding preference similarity constant. Their study on California Marine Protected Area Policy reveals that "in technical, complex policy subsystems with influential organizational affiliations that control resources, actors have to get some advice/information and coordinate somewhat with influential affiliations - irrespective of beliefs" (Weible and Sabatier, 2005, 471). This interpretation follows resource dependence theory (Pfeffer and Salancik, 1978), which states that organizations have to establish contacts to well-resourced organizations to maintain their survival in a world of scarce resources. Applied to politics, actors seek alliances with actors who are in control of formal decision-making power or informal, but extensive, access to relevant decisionmakers. 
To link influence reputation back to the discussion of preference similarity and strategies of actors, the empirical result "would indicate that stakeholders are interacting to some extent with other actors of divergent beliefs" (Weible and Sabatier, 2005, 471). At least to a certain extent this would challenge the basic assumption of the Advocacy Coalition Framework that coordination takes place within coalitions. Our models hence include a control variable for the perceived influence of potential peer organizations.

\section{Influence of third parties on information exchange}

Network ties are rarely independent from each other. If $\mathrm{A}$ is connected to $\mathrm{B}$ and $\mathrm{C}$, then this may also affect the likelihood of $\mathrm{B}$ being connected to C. Modeling the dependencies is in fact the primary goal of statistical social network analysis; the autocorrelation resulting from those dependencies is not just an obstacle to be ruled out. Having this framework in mind, Carpenter et al. (2004) explicitly analyze the role of third-party connections for dyadic relationships. More precisely, they test a number of triad configurations and find that transitivity is a particularly relevant element of contact-making, meaning that actor $\mathrm{A}$ is more likely to interact with actor $\mathrm{B}$ if $\mathrm{A}$ interacts with a third party $\mathrm{C}$ who also interacts with $\mathrm{B}$. In network terminology, directed two-paths between two actors have an effect on their tie probability. Carpenter et al. interpret this kind of transitivity as "social trust" and "social capital": actors need common "friends" to reduce uncertainty about the quality of their contact. As Carpenter et al. (2004, 230) put it,

"groups are constantly searching for good sources of information. That is, interest groups are not simply transmitting information about politics and policy, but also about who are reliable sources of information. Presumably, most interest groups consider their sources of information to be reliable (otherwise, why get information from them?) and report this to other groups with whom they communicate. There is thus a dynamic tendency to create transitive relationships: A communicates to $\mathrm{B}$, which is satisfied with the information it gets from $\mathrm{A}$, and reports this to $\mathrm{C}$, which subsequently seeks information from A."

This kind of social behavior is typical when actors exchange strategic information about policy goal attainment and related topics. We therefore include a transitivity-related control variable which checks whether the number of directed two-paths between two actors in the political/strategic information exchange network positively affects their likelihood of establishing a direct tie. 
Similarly, the Advocacy Coalition Framework hypothesizes that organizations show coordinated behavior and that coordination and learning from each other take place within coalitions (Sabatier and Weible, 2007). Thus, actors are more likely to trust information from another organization if it is in the same coalition. Common neighborhood clearly matters. The same argument is put forth by Carpenter et al. (2004, 227): "When an issue is both complex and newly emergent, [...] policy actors will engage in discussion in order to establish a frame of reference within which preferences may be defined. [...] To the extent that policy communication is this sort of mutual construction of issue interpretations, social properties such as friendship, trust, sharing common frames of reference, and other social similarities will increase the likelihood of communication."

Such a view presupposes that transitivity not only matters when considering strategic communication; it expands to technical or scientific information as well because actors use such information to construct a coalition and its corresponding frame of reference. However, this is at odds with the policy maximization model cited earlier on (Stokman and Zeggelink, 1996), which implies that technical information is sent to adversarial coalitions, rather than being distributed within the actor's own coalition. Consequently, clustering and thus triad formation and transitivity should be significantly less marked than in the strategic information exchange network.

We therefore keep in mind that this is a challenged view when formulating our next control variable according to the Advocacy Coalition Framework and the reference frame construction hypothesis of Carpenter et al. (2004): we check whether the number of directed two-paths between two actors in the technical/scientific information exchange network positively affects their likelihood of establishing a direct tie.

\section{Data collection and methodology}

The previous section has provided a literature review of theoretical and empirical studies contributing to the analysis of information exchange between policy elites. We have compiled a list of hypotheses from previous works and also generated genuinely new hypotheses by linking several theories from other fields. These hypotheses shall be tested with a dataset on toxic chemicals regulation in Germany in the 1980s collected by one of the authors (Schneider, 1988). This section will introduce the case of toxic chemicals policy-making and describe the data collection process. 


\subsection{The toxic chemicals problem}

After World War II, the production of chemicals increased to an unprecedented level. Approximately 100,000 different chemical substances were traded on the global market. Many of these chemicals were evidently extremely dangerous for human health and the environment, sometimes in the form of insidious diseases or after long-term contact. At the beginning of the 1970s, most industrialized countries adopted the view that a passive treatment of these toxic substances was no longer affordable. They initiated chemicals control programs and testing procedures for chemical substances. Forerunners of this trend were the Swiss toxic substances law ("Giftgesetz") in 1969 and similar laws in Japan and Sweden in 1973.

In Germany, a legislative process was started mainly upon the initiative of the OECD and the European Community at the end of the 1970s. The effort culminated in the adoption of a law for the protection against dangerous substances (ChemG) in 1980. However, this law was restricted to the control of newly produced chemicals without considering toxic substances already on the market. This restriction was intended by the chemical industry because it feared fatal economic consequences if control obligations were extended to existing chemicals. The chemical industry association (VCI) took a lead position in this process because it possessed the representational monopoly of economic and industrial interests in this policy domain, and these were in turn major employers and investors on the global market. The chemical industry was not only a growth sector; to a certain degree, it also promised a future-proof development due to its structural closeness to genetic research, biotechnology and related industrial branches.

\subsection{Selection of actors}

As the main point of reference of this system of policy actors was the chemicals problem and its direct and indirect effects, it was possible to define a set of interested actors. As far as direct influences in the life cycle of a chemical are concerned, occupational safety, health and environmental interests were potentially affected by the toxicity of the substances. Moreover, a set of governmental actors was bound to react to the politicization of the problem by these societal actors. It is therefore quite easy to derive the following set of actors on theoretical and institutional grounds: the state, parties/the parliament, organized interests (capital, labor, environment and consumers) and finally actors from science and technology.

Methods from elite research were applied to conduct a proper specification of the boundaries of the network (c.f. Laumann et al., 1983). This 
task was not negligible because the results of a network analysis critically depend on the valid and reliable selection of actors. The positional approach served to compile a list of all possible organizations from institutional sectors that were potentially affected by the problem of toxic chemicals. The names of these organizations were collected from relevant handbooks about public organizations and the list of lobbyists in the German parliament. At the second stage of the selection procedure, press archives, lists of participants of relevant events, and protocols and documents of relevant agencies and ministries were surveyed to confirm or discard the actual participation of organizations, and some new actors were added. This second stage is called the decision approach. The resulting list contained 90 organizations that were asked to submit annual reports, position papers, press releases and other relevant documents. On the basis of these documents and a number of expert interviews, 39 organizations were selected and asked to fill out a standardized questionnaire in the winter of 1984/1985, following the approach of Laumann and Knoke (1987) and Laumann and Pappi (1976). Eight more actors were named by the interviewees. The response rate was $85 \%$ (40 out of the 47 actors). To obtain a complete influence core from this actor set, only those 30 actors were retained who were cited as being influential by at least one of the other actors. This final list of actors is composed of eleven governmental actors (among them six federal ministries), three parties, seven organized interest groups, six scientific/research organizations and three international organizations. Further details about the actors and the data collection process are provided by Schneider (1988).

The set of 30 actors is somewhat smaller than the datasets used in some of the other articles. However, the careful data collection procedure ensures a high quality of the data in terms of reliability and validity. Since the two networks to be modeled are directed and we concentrate on edges as the unit of analysis, there are $n^{2}-n=870$ observations which are partly dependent on each other, so the real number of observations might be smaller than 870 .

\subsection{Measurement and variables}

The two network relations of interest are political/strategic and scientific/technical information exchange. The political/strategic information exchange network was collected by setting the following task: ${ }^{2}$

\footnotetext{
${ }^{2}$ The original questionnaire was in German. The questions have been translated for this article.
} 
"Please list the names of all organizations with whom you regularly exchange information about affairs related to chemicals control."

This network does not contain information about who sends information to whom, but it is still directed because actors indicate whom they perceive to be information exchange partners. The technical/scientific information exchange network was collected by asking respondents the following questions:

"In the decision process on the chemicals law, scientific and technical information were of central importance.

a) From which of the organizations mentioned on the list does your organization usually obtain scientific and technical information?

b) To which of the organizations does your organization deliver such information?"

These two separate pieces of information about sending and receiving technical/scientific information were combined in a single network matrix $\mathbf{T}$ by multiplying the entries of the sender matrix $\mathbf{S}$ with the entries of the transpose of the receiver matrix $\mathbf{R}$ (i. e., the Hadamard product). The result is a confirmed network:

$$
\mathbf{T}:=\mathbf{S} \odot \mathbf{R}^{T}
$$

Preference similarity was measured by identifying six core policy topics relevant in the decision process: self-regulation, the scope of the reform, the control procedure, the timing of the control mechanism, intensity of control, and the treatment of chemicals already being traded on the market (please refer to the original study for more details). For all actors, agreement or disagreement with each issue was coded either as +1 (agreement), 0 (neutrality), or -1 (disagreement). The resulting variables $i \ldots n$ were used to construct a dissimilarity matrix by calculating the Euclidean distance $d$ between each pair of actors $p$ and $q$ :

$$
d(p, q)=\sqrt{\sum_{i=1}^{n}\left(p_{i}-q_{i}\right)^{2}}
$$

The dissimilarity matrix was converted into a similarity matrix by subtracting each dissimilarity value from the maximum dissimilarity value:

$$
s(p, q)=\max (d)-d(p, q)
$$


The resulting matrix of preference similarities between actors can be interpreted as an undirected, weighted network, which can subsequently be used as an edge covariate in a statistical network model.

Perceived influence was collected as a binary, directed network matrix with the row actor indicating what column actors it perceived as influential. Membership in policy committees was collected from the various documents surveyed during the selection process and recorded as binary attribute variables in a data matrix $\mathbf{M}$. A square co-occurrence matrix $\mathbf{C}$ was generated, indicating which pairs of actors attended how many committees together:

$$
\mathbf{C}:=\mathbf{M} \cdot \mathbf{M}^{T}
$$

\subsection{Methodology and model specification}

The purpose of this article is two-fold: on the one hand, a statistical network model will be employed to test the hypotheses set out in section 2 . On the other hand, the goal is to model the information exchange behavior of political actors as adequately as possible, so we are eventually able to reproduce the tie formation process using simulations.

As mentioned earlier on, networks show complex dependencies between ties, resulting in matrix autocorrelation. In other words, the error terms in a simple OLS regression would be correlated across observations, standard errors would be too small and $p$ values too optimistic. There are two solutions to avoid this problem: one is to correct for the autocorrelation by employing the quadratic assignment procedure (Krackhardt, 1988), and the other solution is to model the dependencies directly as a social network. We take the latter approach and draw on the family of exponential random graph models (ERGM), or p* models, described by Robins et al. (2007a,b) and implemented in the statnet package (Handcock et al., 2003) for the statistical computing environment $\mathrm{R}$ ( $\mathrm{R}$ Development Core Team, 2009). The general form of exponential random graphs can be written as

$$
\operatorname{Pr}(\mathbf{Y}=\mathbf{y})=\left(\frac{1}{\kappa}\right) \exp \left\{\sum_{A} \eta_{A} g_{A}(\mathbf{y})\right\}
$$

with $\mathbf{y}$ representing a tie in the network $\mathbf{Y}, \kappa$ being a normalizing constant, $g_{A}(\mathbf{y})$ representing the model terms listed in table 1 ( $A$ is the index of the model terms), and $\eta_{A}$ being the coefficients of the model terms. In order to model our two information exchange networks $\mathbf{Y}_{1}$ and $\mathbf{Y}_{2}$, we estimate a dyadic dependence model with the model terms listed in table 1.

The model is fitted via Markov Chain Monte Carlo Maximum Likelihood Estimation (MCMC MLE). The estimated coefficients can be interpreted 


\begin{tabular}{|c|c|c|}
\hline$L(y)$ & $\begin{array}{l}\text { a term containing the number of edges in the graph, } \\
\sum_{i<j} y_{i j}\end{array}$ & \\
\hline$P S(y)$ & $\begin{array}{l}\text { an undirected, weighted edge covariate representing } \\
\text { preference similarity as calculated by equation } 3\end{array}$ & $\mathrm{H}_{1}$ \\
\hline$I F_{\text {gov }}(y)$ & $\begin{array}{l}\text { a statistic representing ties where the target is a govern- } \\
\text { mental actor }\end{array}$ & $\mathrm{H}_{2 \mathrm{a}}$ \\
\hline$O F_{s c i}(y)$ & $\begin{array}{l}\text { a statistic representing ties where the source is a scien- } \\
\text { tific actor }\end{array}$ & $\mathrm{H}_{2 \mathrm{~b}}$ \\
\hline$C(y)$ & $\begin{array}{l}\text { an undirected, weighted edge covariate representing the } \\
\text { number of common committee memberships as defined } \\
\text { in equation } 4\end{array}$ & $\mathrm{H}_{3 \mathrm{a}}$ \\
\hline$O(y)$ & $\begin{array}{l}\text { a directed, binary edge covariate representing the other } \\
\text { communication type not represented by } \mathbf{Y} \text { (scienti- } \\
\text { fic/technical or political/strategic communication) }\end{array}$ & $\mathrm{H}_{3 \mathrm{~b}}$ \\
\hline$U_{i g}(y)$ & $\begin{array}{l}\text { a nodal attribute mixing statistic representing ties where } \\
\text { both the source and the target are interest groups }\end{array}$ & $\mathrm{C}_{1}$ \\
\hline$I A(y)$ & $\begin{array}{l}\text { a directed, binary edge covariate representing influence } \\
\text { attribution }\end{array}$ & $\mathrm{C}_{2}$ \\
\hline$v\left(y, \theta_{1}\right)$ & $\begin{array}{l}\text { GWESP, the geometrically weighted edge-wise shared } \\
\left.\text { partner statistic with parameter } \theta_{1} \text {; see Hunter ( } 2007\right) \\
\text { for details; we use a rather low value of } \theta_{1}=0.1 \text { to avoid } \\
\text { model degeneracy }\end{array}$ & $\mathrm{C}_{3 \mathrm{a}}$ \\
\hline$w\left(y, \theta_{2}\right)$ & $\begin{array}{l}\text { GWDSP, the geometrically weighted dyad-wise shared } \\
\text { partner statistic with parameter } \theta_{2}=0.1\end{array}$ & $\mathrm{C}_{3 \mathrm{~b}}$ \\
\hline
\end{tabular}

Table 1: Model terms and their affiliated hypotheses or control variables

like in a logit regression model. The dependent variable is the log odds of establishing a network tie. Coefficients are interpreted as log-odds ratios conditional on the rest of the network.

\section{Results and discussion}

\subsection{Results of the analysis}

Table 2 shows the estimation results for four models. The first two are models of political/strategic information exchange, and the last two of technical/scientific information exchange. The edge term $L(y)$ is comparable to the constant in other statistical models. The first and the third model 


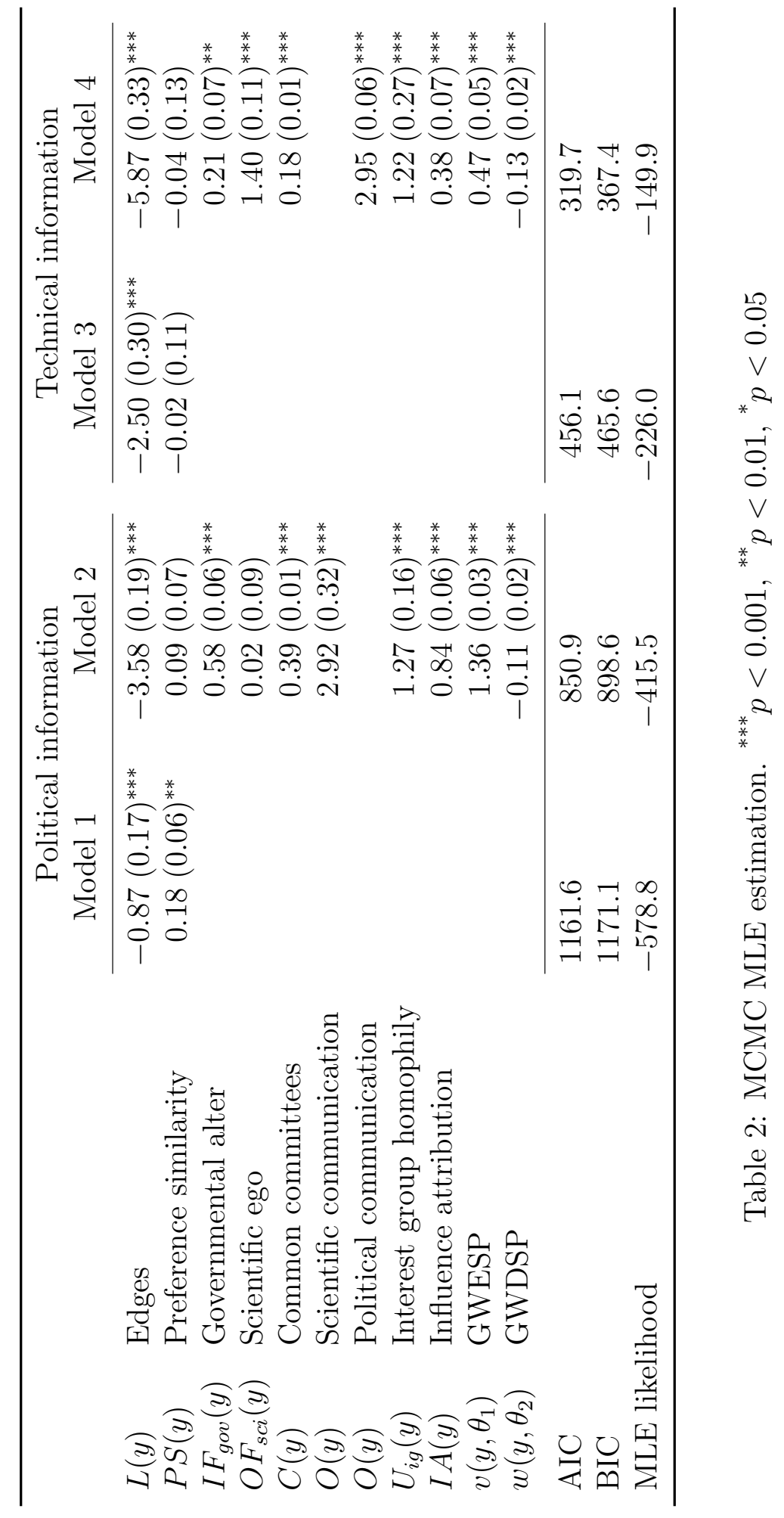


are limited to estimating the effect of preference similarity on information exchange.

In the case of political/strategic information, tie formation is indeed positively associated with preference similarity, while there is no association whatsoever in the case of technical/scientific information, but the sign of the coefficient at least meets the prediction of hypothesis $1 \mathrm{~b}$. The former observation is in accordance with the policy maximization model and the Advocacy Coalition Framework, which posit that strategic information is exchanged primarily among allies. The fact that there is no effect in the second case indicates that the association between preferences and technical information exchange might be somewhat more complex than the policy maximization model and the Advocacy Coalition Framework assume. Technical information are not merely used to influence the opponent; they are also used to construct a common frame of reference, as Carpenter et al. (2004) have pointed out. However, if we take any other explanatory factor into account, the positive effect of model 1 disappears. Preference similarity is absorbed by other factors, which are captured by models 2 and 4. Hypothesis 1 a can therefore only partly be confirmed, and hypothesis $1 \mathrm{~b}$ is not supported.

As for the nodal attribute hypotheses $2 \mathrm{a}$ and $2 \mathrm{~b}$, governmental actors are clearly the addressees of both scientific/technical and political/strategic information. This effect is slightly more pronounced in the political network, which is probably due to the fact that for interest groups, governmental actors are slightly more interesting as allies than as lobbying targets. However, both relations are strongly affected. As expected, scientific actors are a major source of scientific/technical information while their political or strategic output is not particularly high (but not particularly low either; otherwise the coefficient would be negative and significant).

Opportunity structures are strong predictors of tie formation with all four coefficients being highly significant and positive (hypotheses 3 a and $3 \mathrm{~b}$ ). Actors who belong to the same policy committees are more likely to exchange both types of information, presumably because their transaction costs are low. If two organizations exchange one type of information, they are also much more likely to exchange the other kind of information as well because the transmission channels exist anyway. This is in line with resource dependence theory and social movement mobilization theory (c. f. section 2.3).

The nodal mixing control variable 1 has positively significant coefficients. In both networks, interest groups are more likely than chance to exchange information among each other. This finding is compatible with the Advocacy Coalition Framework as interest groups are the core actors in each coalition because their interests are at stake. Whether positive signals (allianceseeking) or negative signals (influencing each other), organized interests are 
particularly likely to clump together, a finding that is also supported by some theories of interest intermediation, like neo-corporatism.

Influence attribution plays a major role in choosing interaction partners. The positive and strongly significant coefficients confirm the predictions of Austen-Smith and Wright (1992) and the control maximization model of Stokman and Berveling (1998) - although the authors actually find little support for their model. We can thus corroborate the finding of Weible and Sabatier (2005) that perceived influence positively affects peer choice, a finding which also supports the prediction of resource dependence theory that organizations strive for influential contacts to maintain their survival. The Advocacy Coalition Framework assumes that coordination takes place within coalitions; however, this assumption must be qualified by taking influence into account.

Finally, transitivity effects of third parties can be clearly demonstrated as well. The geometrically weighted edge-wise shared partner distribution (GWESP) and the geometrically weighted dyad-wise shared partner distribution (GWDSP) can be interpreted together (Hunter, 2007). The GWESP statistic essentially captures whether those actors who are tied are more likely than pure chance to have multiple transitive shared partners. GWDSP captures the propensity of any dyad (whether connected or unconnected) to have multiple transitive shared partners, which is sort of a baseline effect of shared partners in the network. GWESP is interpreted on top of that once dyad-wise shared partners have been controlled for. GWESP and GWDSP have a geometric character, i.e., the number of shared partners per dyad is weighted by $\theta_{1}=\theta_{2}=0.1$. This rather low parameter value puts more emphasis on dyads with few shared partners: dyads with one shared partner are not particularly likely to have a second shared partner, and so on.

The GWESP statistic is positive and highly significant in both networks, indicating that social trust and social capital effects are at work. Connected dyads are indeed likely to have approximately one or two transitive shared partners. GWDSP is significant and negative, i. e., there are generally fewer unconnected dyads with shared partners than predicted by chance. Transitivity effects are not only expected by social capital theory, but can also be derived from the Advocacy Coalition Framework: actors self-organize in coalitions, so there are many transitive shared partners. In contrast, the policy maximization model of Stokman and Berveling (1998) would have expected contact-seeking between opponents, so there should be no transitive shared-partner effect in the technical information exchange network. Our evidence suggests that the policy maximization model is wrong in this respect. 


\section{Goodness-of-fit diagnostics}
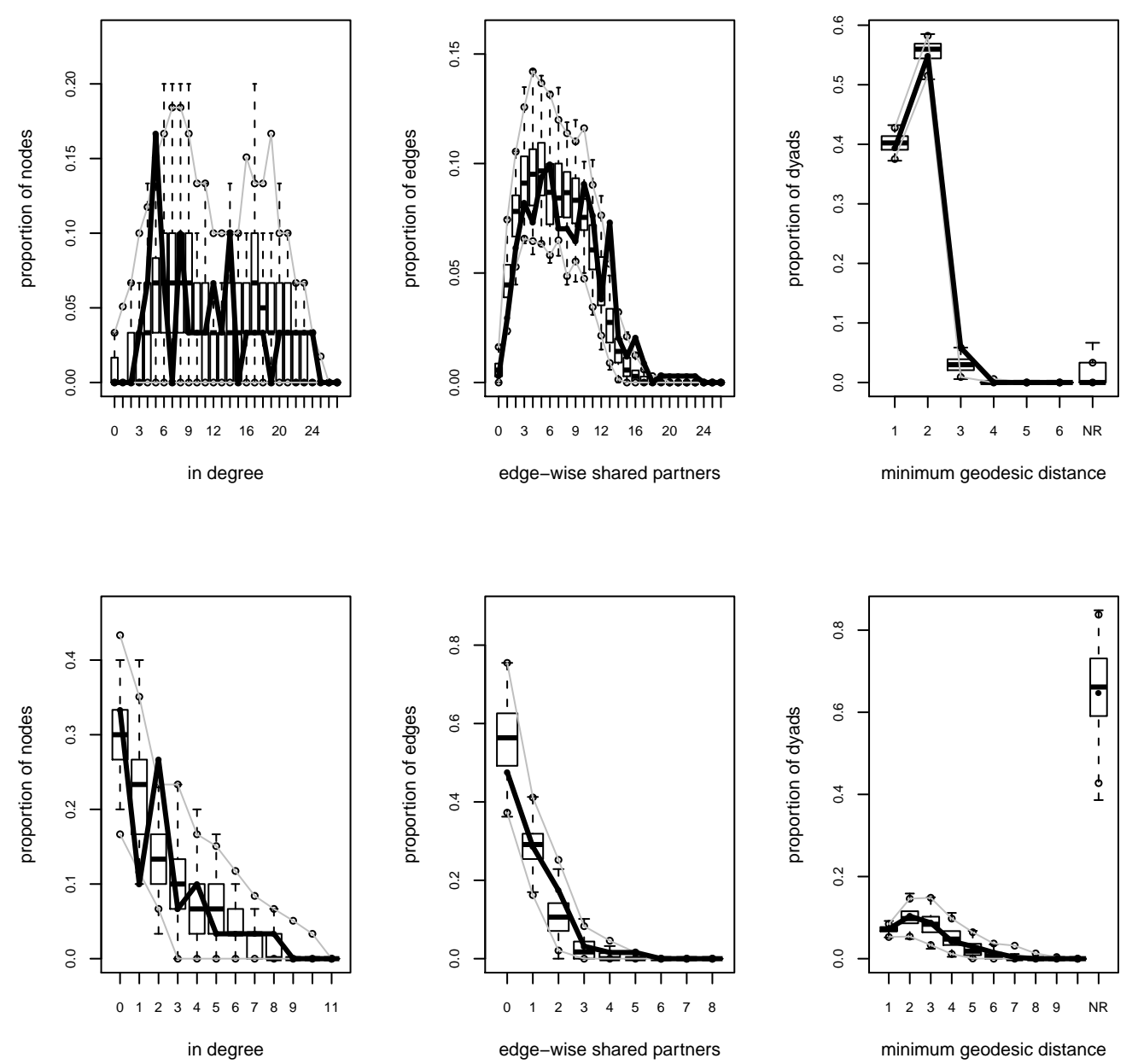

Figure 1: Goodness of fit of the political information exchange model (upper row) and the technical information exchange network (lower row)

\subsection{Goodness-of-fit assessment}

As stated at the outset of this article, our primary goal is to find an appropriate model of information exchange. Obviously, this should entail assessing the goodness of fit of our model by simulating new networks from our coefficients. Simulating 100 networks from each of the two complete models shows that the simulated networks are indistinguishable from the original networks by eyeballing them. To support this claim, figure 1 plots three well-known network statistics of the original network (the thick black line) and the 100 
simulated networks (the box plots): indegree, minimum geodesic distance, and edge-wise shared partners (see Hunter et al., 2008, for details).

The indegree distribution of the original political network takes a zigzag curve which can be hardly caught by a parametric model. However, the model is not terribly off the mark. Only indegrees of five, which seem to be quite common in the network, are strongly underrepresented by the model. Nevertheless, adding a network statistic for indegrees of five would certainly mean overfitting the model because there is no guidance in the literature why actors should have five incoming ties, even more so given the much lower frequencies of its neighboring indegrees four and six. The indegree distribution of the technical network exhibits similar variation, but the simulated distributions seem to represent the original network quite well if we consider the overall picture. The other two statistics, minimum geodesic distance and edge-wise shared partners, perform extremely well, with the case of zero edge-wise shared partners being slightly overrepresented by the second model.

Overall, the estimated models fit the data very well and seem to capture most of the variation. All three simulated graph statistics predict the original networks with high accuracy. This is a noteworthy finding because we seem to have incorporated all of the relevant factors contributing to network formation. Such an undertaking is especially difficult in policy-related applications because many layers of complexity are added by different rationales of actors, institutional roles and constraints, voters, media discourses, etc.

\section{Conclusion}

First and foremost, our analysis has revealed the effect of opportunity structures on tie formation in policy networks. We have operationalized the effect by counting co-membership in policy committees and by estimating the impact of complementary types of information exchange relations. To the best of our knowledge, this effect has not previously been demonstrated empirically. According to our interpretation, political organizations take transaction costs into account when considering whom to approach. When actors choose potential interaction partners because they are important in attaining policy-related goals, they also consider if these potential exchange partners are easy to reach. Our finding suggests that politics is not merely powerdriven, but also resource-dependent. This bears some interesting policy implications: if the state is interested in balancing organized interests in order not to be captured (this alludes to pressure pluralism versus the capture theory; c.f. van Waarden, 1992), it may want to promote civil society groups 
that cannot afford to take part in the inner circle of sectoral politics. Otherwise one coalition might become more influential in the political process because its members are well connected, and this coalition might bias political outcomes into their desired direction. This is precisely what happened in the case of German toxic chemicals regulation in the early 1980s (c.f. Schneider, 1988, for details). This normative approach is not new; it is wellknown under the label sponsored pluralism (c.f. van Waarden, 1992). Please note, however, that subsidizing organized interests selectively to keep up the balance may have negative welfare implications as well. Economic scrutiny may show whether political gains of a balanced interest group population outweigh efficiency losses due to the subsidies. This is beyond the scope of this article.

Secondly, we have assembled a rather rich model of policy network formation by recycling bits and pieces of previous policy network studies and related literature and combining them with variables measuring opportunity structures of political actors. The model fits the data very well, and we are confident that we have contributed to the advancement of the literature on policy networks by providing a baseline model for potential replications in other policy sectors or other contexts. After all, any policy network study can only be a case study, and other policy networks might operate quite differently due to other institutional contexts, so this is certainly a worthwhile endeavor. Technological advances like the rise of personal computers and internet communication may nowadays affect the way political organizations interact, rendering the necessity of reducing transaction costs via policy committees or other factors meaningless.

Thirdly, we have suggested that there is not one single way how a policy network operates. To the contrary, the exchange of technical information differs from strategic information in some respects. Previous studies on "tie formation in policy networks" tended to ignore this possibility, and information exchange was treated as a homogeneous phenomenon. Nonetheless, the main effects are consistent across the two relations; only institutional roles and preference similarity show different patterns. Reviewing the relevant theoretical literature has, in spite of this, suggested that the two types of relations partly differ in their rationales, but not in their consequences for tie formation patterns. For instance, technical information is often exchanged with allies because they try to establish a common frame of reference (a cooperative relation). At the same time, technical information is also exchanged with opponents, but this time in order to alter their views on optimal policy design (a conflictual relation). Thus the overall effect of preference (dis)similarity cannot be discerned simply by measuring technical information exchange, and the effect cannot be separated from strategic information 
exchange. We therefore propose that future policy network analyses should take these strategic uses of information into account when collecting data on information exchange between organizations.

\section{References}

Adam, S. and Kriesi, H. (2007). The Network Approach. In Sabatier, P. A., editor, Theories of the Policy Process, chapter 5, pages 129-154. Westview Press, Boulder, CO.

Austen-Smith, D. and Wright, J. R. (1992). Competitive Lobbying for a Legislator's Vote. Social Choice and Welfare, 9(3):229-257.

Carpenter, D. P., Esterling, K. M., and Lazer, D. M. (2004). Friends, Brokers, and Transitivity: Who Informs whom in Washington Politics? The Journal of Politics, 66(1):224-246.

Handcock, M. S., Hunter, D. R., Butts, C. T., Goodreau, S. M., and Morris, M. (2003). statnet: Software Tools for the Statistical Modeling of Network Data. Seattle, WA. http://statnetproject.org.

Heclo, H. (1978). Issue Networks and the Executive Establishment. In King, A., editor, The New American Political System, pages 87-124. American Enterprise Institute, Washington, D.C.

Henry, A. D., Lubell, M., and McCoy, M. (2010). Ideology and Social Capital as Drivers of Policy Network Structure. Unpublished Manuscript.

Huckfeldt, R. and Sprague, J. (1987). Networks in Context: The Social Flow of Political Information. The American Political Science Review, 81(4):1197-1216.

Hunter, D. R. (2007). Curved Exponential Family Models for Social Networks. Social Networks, 29(2):216-230.

Hunter, D. R., Goodreau, S. M., and Handcock, M. S. (2008). Goodness of Fit of Social Network Models. Journal of the American Statistical Association, 103(481):248-258.

Kitschelt, H. P. (1986). Political Opportunity Structures and Political Protest: Anti-Nuclear Movements in Four Democracies. British Journal of Political Science, 16:57-85. 
Krackhardt, D. (1988). Predicting with Networks: Nonparametric Multiple Regression Analysis of Dyadic Data. Social Networks, 10(4):359-381.

Kriesi, H. (1995). The Political Opportunity Structure of New Social Movements: Its Impact on their Mobilization. In Jenkins, J. C. and Klandermans, B., editors, The Politics of Social Protest: Comparative Perspectives on States and Social Movements, pages 167-198. University of Minnesota Press, Minneapolis.

König, T. and Bräuninger, T. (1998). The Formation of Policy Networks: Preferences, Institutions and Actors' Choice of Information and Exchange Relations. Journal of Theoretical Politics, 10(4):445-471.

Laumann, E. O. and Knoke, D. (1987). The Organizational State: Social Choice in National Policy Domains. University of Wisconsin Press, Madison.

Laumann, E. O., Marsden, P. V., and Prensky, D. (1983). The Boundary Specification Problem in Network Analysis. In Burt, R. S. and Minor, M. J., editors, Applied Network Analysis: A Methodological Introduction, pages 18-34. Sage Publications, London.

Laumann, E. O. and Pappi, F. U. (1976). Networks of Collective Action: A Perspective on Community Influence Systems. Academic Press, New York.

Laumann, E. O., Tam, T., Heinz, J. P., Nelson, R. L., and Salisbury, R. H. (1992). The Social Organization of the Washington Establishment during the first Reagan Administration. In Moore, G. and Whitt, J. A., editors, The Political Consequences of Social Networks, volume 4 of Research in Politics and Society. A Research Annual, pages 161-188. JAI Press, Greenwich, CT.

Leifeld, P. (2007). Policy Networks: A Co-Citation Analysis of the Quantitative Literature. Master's thesis, University of Konstanz, Department of Politics and Management.

McPherson, M., Smith-Lovin, L., and Cook, J. M. (2001). Birds of a Feather: Homophily in Social Networks. Annual Review of Sociology, 27(1):415-444.

Pfeffer, J. and Salancik, G. R. (1978). The External Control of Organizations: A Resource Dependence Perspective. Harper \& Row, New York.

Pielke, R. A. (2007). The Honest Broker: Making Sense of Science in Policy and Politics. Cambridge University Press, Cambridge. 
R Development Core Team (2009). R: A Language and Environment for Statistical Computing. R Foundation for Statistical Computing, Vienna, Austria. http://www.R-project.org.

Robins, G., Pattison, P., Kalish, Y., and Lusher, D. (2007a). An Introduction to Exponential Random Graph ( $\left.\mathrm{p}^{*}\right)$ Models for Social Networks. Social Networks, 29(2):173-191.

Robins, G., Snijders, T. A., Wang, P., Handcock, M., and Pattison, P. (2007b). Recent Developments in Exponential Random Graph (p*) Models for Social Networks. Social Networks, 29(2):192-215.

Sabatier, P. A. (1987). Knowledge, Policy-Oriented Learning, and Policy Change: An Advocacy Coalition Framework. Science Communication, 8(4):649-692.

Sabatier, P. A. and Weible, C. M. (2007). The Advocacy Coalition Framework. In Sabatier, P. A., editor, Theories of the Policy Process, pages 189-220. Westview Press, Boulder, CO.

Schneider, V. (1988). Politiknetzwerke der Chemikalienkontrolle: Eine Analyse einer transnationalen Politikentwicklung. de Gruyter, New York/Berlin.

Schneider, V. and Leifeld, P. (2009). Überzeugungssysteme, Diskursnetzwerke und politische Kommunikation: Ein zweiter Blick auf die deutsche Chemikalienkontrolle der 1980er Jahre. In Schneider, V., Janning, F., Leifeld, P., and Malang, T., editors, Politiknetzwerke. Modelle, Anwendungen und Visualisierungen, pages 139-158. VS Verlag für Sozialwissenschaften, Wiesbaden.

Stokman, F. N. and Berveling, J. (1998). Dynamic Modeling of Policy Networks in Amsterdam. Journal of Theoretical Politics, 10(4):577-601.

Stokman, F. N. and Zeggelink, E. P. H. (1996). Is Politics Power or Policy Oriented? A Comparative Analysis of Dynamic Access Models in Policy Networks. Journal of Mathematical Sociology, 21(1-2):77-111.

Streeck, W. and Schmitter, P. C. (1985). Community, Market, State - and Associations? The Prospective Contribution of Interest Governance to Social Order. European Sociological Review, 1(2):119-138.

van Waarden, F. (1992). Dimensions and Types of Policy Networks. European Journal of Political Research, 21(1):29-52. 
Weible, C. M. and Sabatier, P. A. (2005). Comparing Policy Networks: Marine Protected Areas in California. Policy Studies Journal, 33(2):181202.

Williamson, O. E. (1991). Comparative Economic Organization: The Analysis of Discrete Structural Alternatives. Administrative Science Quarterly, 36(2):269-296.

Williamson, O. E. (2000). The New Institutional Economics: Taking Stock, Looking Ahead. Journal of Economic Literature, 38(3):595-613.

Zafonte, M. and Sabatier, P. A. (1998). Shared Beliefs and Imposed Interdependencies as Determinants of Ally Networks in Overlapping Subsystems. Journal of Theoretical Politics, 10(4):473-505. 